\title{
Influences of West Pacific Sea Surface Temperature on Covarying Eurasian Droughts Since the Little Ice Age
}

\author{
Huanhuan Li ${ }^{1,2}$, Keyan Fang ${ }^{2,3, *}$, Jianhua Du ${ }^{4}$, Feifei Zhou ${ }^{2}$, Zhipeng Dong ${ }^{2}$, Peng Zhang ${ }^{3}$ \\ and Gang Huang 5,6,*iD \\ 1 School of Atmospheric Sciences, Chengdu University of Information Technology, Chengdu 610225, China; \\ uniquelihh@163.com \\ 2 Key Laboratory of Humid Subtropical Eco-Geographical Process (Ministry of Education), Fujian Normal \\ University, Fuzhou 350007, China; chenqy_gogo@126.com (F.Z.); dongzhipeng170@163.com (Z.D.) \\ 3 Regional Climate Group, Department of Earth Sciences, University of Gothenburg, \\ Box 460 S-405 30 Gothenburg, Sweden; peng.zhang@gu.se \\ 4 Fire Management Office, Ministry of Emergency Management, People's Republic of China, \\ Beijing 100054, China; du_jian_hua@yeah.net \\ 5 State Key Laboratory of Numerical Modeling for Atmospheric Sciences and Geophysical Fluid Dynamics, \\ Institute of Atmospheric Physics, Chinese Academy of Sciences, Beijing 100029, China \\ 6 University of Chinese Academy of Sciences, Beijing 100049, China \\ * Correspondence: kfang@fjnu.edu.cn (K.F.); hg@mail.iap.ac.cn (G.H.); Tel.: +86-1845-915-8986 (K.F.); \\ +86-10-82995312 (G.H.)
}

Received: 7 November 2019; Accepted: 24 April 2020; Published: 3 June 2020

\begin{abstract}
The Western Pacific Warm Pool (WP), with the highest sea surface temperature (SST) in the world, has strong impacts on the drought variations in Eurasia. However, since the little ice age (1250-1850, LIA), the co-climatic drought pattern due to WP warming in Eurasia remains unclear. This is a long-term warming background for the current warming period (CWP). In this paper, we use both instrumental data and 1625 tree-ring width records from Eurasia to investigate the drought patterns in both modern and historical periods. This study revealed two seesaw precipitation patterns, namely the Central Asia-Mongolia (CAMO) and Northern Europe-Southern Europe (NESE) patterns. When the Western Pacific Warm Pool sea surface temperature (WPSST) is high, precipitation increases in Central Asia and Northern Europe, and decreases in Mongolia and southern Europe. When the positive (negative) phase event of the El Niño-Southern Oscillation (ENSO) occurs, the WPSST is reduced (increased), and the decreases (increases) of precipitation in Central Asia and Northern Europe and the increases (decreases) in precipitation in Mongolia and southern Europe are more obvious. The CAMO dipole has been strengthened since the LIA. The CAMO dipole is positively correlated with solar radiation and Northern Hemisphere temperature, and negatively correlated with Pacific decadal oscillations (PDO).
\end{abstract}

Keywords: drought; tree ring; Western Pacific Warm Pool (WP); Eurasia; Pacific decadal oscillations (PDO)

\section{Introduction}

Global warming has changed the water cycle, such as increasing the frequency and intensity of global droughts and floods [1]. Assessing drought trends in the context of global warming is particularly important, because the economic costs of drought far outweigh the costs of other natural disasters in the context of global warming [2].

A great deal of research has been done to investigate the temporal and spatial variations of drought and the relationships between variations in different regions. Some studies have shown that the Western Pacific Warm Pool sea surface temperature (WPSST) affects the drought patterns in 
Eurasia [3-5]. The Western Pacific Warm Pool (WP) was covered by a thick surface of warm water, which is an important source of global heat and water [6]. The hydrological changes in WP are closely related to the high latitude climate change via modulating large-scale circulation systems [3,7-9]. Studies $[5,10]$ indicated that convective heating anomalies near the western Pacific and the Philippines establish a link between East Asian and northwestern Pacific climates. Yan and Li [11] showed that convection in the tropical western Pacific in summer has an important influence on the precipitation in the middle and lower reaches of the Yangtze River by modulating the subtropical high and the East Asian summer monsoon. Zhang et al. pointed out that La Niña, a warmer-than-normal WPSST, often caused North Atlantic oscillation (NAO) positive anomalies and enhanced North Atlantic jet streams, resulting in a wet north and dry south of Europe [2]. At the interdecadal (10-100 year) scale, it has also been observed that the increase of the WPSST is positively associated with NAO [12-14].

Although many studies based on instrumental records have explored the response of precipitation in Eurasia to WPSST, they are still unclear about the covarying drought patterns and their regimes in pre-industrial periods when the human impacts were weakened. This requires long-term proxy data. The warming in recent decades is based on the warming background since the little ice age (1250-1850, LIA), and the period from the LIA to the contemporary warm period is the most significant warming period in the last millennium [15]. In addition, comparisons between the dry and wet changes in Eurasia, where human activity was relatively weak before industrialization, and the current warming period (CWP) are helpful in assessing the natural and anthropogenic processes of dry and wet changes [15].

A tree-ring proxy is ideal for this study due to its high spatiotemporal resolution, large spatial coverage, long time duration and high climate sensitivity [16]. Tree rings are the most widely used proxy data for studies on climate change over the past millennium. There have been many tree-ring-based drought reconstructions in East Asia and Europe [17-19], but there is still no tree-ring-based study of co-varying drought patterns over the entirety of Eurasia. This study investigates the spatiotemporal hydroclimate characteristics in instrumental and historical periods with special attention to their relationships with WPSST.

\section{Data and Methods}

\subsection{Tree-Ring Data}

We have synthesized 1729 Eurasian tree-ring width chronologies from the International Tree Ring Date Bank (https://www.ncdc.noaa.gov/data-access/paleoclimatology-data/datasets/tree-ring), including the corresponding longitudes, latitudes, start and end years. The tree-ring chronologies were developed after removing the age-related growth trends by fitting in growth curves (a negative exponential curve, straight line or a spline cure with a fixed step size of 100 years, by the ARSTAN program) [20]. We excluded the tree-ring chronologies with an insufficient number of cores ( $<30$ cores) or length ( $<200$ years), resulting in 1625 standard tree-ring chronologies (STD).

\subsection{Meteorological Data}

The monthly total precipitation data used in this study, with a spatial resolution of $0.5^{\circ} \times 0.5^{\circ}$, were from the climate research unit (CRU). We chose data from 1951 because the number of weather records used to generate CRU data in the region was greatly reduced before 1951 [21,22]. Precipitation data has a grid distribution, while tree-ring data is sparse and irregularly scattered. For the convenience of research, the precipitation data are processed into the same position distribution as the tree rings. Most of the tree-ring chronologies end after 1990, and there is less reliable data after 1990. The instrumental data and tree-ring chronology periods studied in this study are from 1951 to 1990.

The SST data is COBE-SST2 monthly average grid data from the National Oceanic and Atmospheric Administration (NOAA), with a total data age of $1850-2015$ and $1^{\circ} \times 1^{\circ}$ spatial resolution [23]. To eliminate the effect of global warming on SST, we removed the trend of SST. According to previous 
research, the square region of the western Pacific $\left(0-18^{\circ} \mathrm{N}, 115^{\circ} \mathrm{E}-150^{\circ} \mathrm{E}\right)$ represents WP $[24,25]$. In this study, the SST in this area is averaged in the meridional and zonal directions, and then the annual average SST is the annual average WPSST.

The $850 \mathrm{hPa}$ potential height field and $850 \mathrm{hPa}$ wind field data are from Reanalysis 1 of National Centers for Environmental Prediction-National Center for Atmospheric Research (NCEP-NCAR). The total age of the data is 1948-2016, and the spatial resolution is $2.5^{\circ} \times 2.5^{\circ}$ [26]. Water vapor is mainly concentrated in the middle and lower layers of the troposphere. An $850 \mathrm{hPa}$ layer is a typical layer. The wind field and potential height field can describe the transportation of water vapor well. The Niño 3.4 indexes from 1951 to 2018 were derived from the National Climate Prediction Center (NCPC). Reconstruction time series of the Pacific decadal oscillation (PDO) [27], solar radiation [28] and temperature in the Northern Hemisphere [29] were obtained from the NOAA.

\subsection{Methods}

Firstly, this study analyzed the response characteristics of precipitation in Eurasia to WPSST from 1951 to 1990. WPSST causes an increase in precipitation in one place and a decrease in precipitation in another place, which are called a pair of precipitation dipoles. At the same time, the response characteristics of precipitation-sensitive tree-ring chronology from 1951 to 1990 to WPSST were combined. We selected the regions that could reflect the impact of WPSST on precipitation with tree-ring chronology and constructed the existing precipitation dipoles. If the dipoles were obvious during the historical period, then we inferred a change of precipitation at this time. We studied the effect of SST anomaly on precipitation in Eurasia by using a complex analysis method. The standard deviation of WPSST from 1951 to 1990 was used as the SST threshold. Years with WPSST above one standard deviation were defined as extremely warm years; years with WPSST below one negative standard deviation were defined as extremely cold years. The effects of extreme sea temperature on precipitation in Eurasia, with and without ENSO events, were studied based on the year in which the ENSO event occurred. Finally, the tree-ring chronology was used to reconstruct precipitation dipoles since the LIA, and to find the factors that affect the dipole changes on an interdecadal scale.

\section{Results and Discussion}

\subsection{Western Pacific Warm Pool Sea Surface Temperature and Precipitation in Eurasia in Instrumental Periods}

We only selected the instrumental records in the grid with nearby ring data to facilitate the comparison between instrument and ring data. A dipole precipitation pattern was observed in Central Asia, with the precipitation in Central Asia positively correlated with the WPSST, and precipitation in Mongolia negatively correlated with the WPSST [30,31]. This was defined as the Central Asia-Mongolia (CAMO) dipole pattern. In Europe, we observed a Northern Europe-Southern Europe (NESE) dipole pattern, with WPSST positively correlated with precipitation in Northern Europe and negatively correlated with that in southern Europe [4,32] (Figure 1a). There was no significant positive correlation between tree chronology and annual precipitation in Siberia (Figure 1b), which limits our ability to detect historically dry dipoles from tree rings. Therefore, the characteristics of precipitation in Siberia are not discussed in this paper.

The first-mode variance contribution rate of the empirical orthogonal function (EOF) analysis of European precipitation is $36.9 \%$ (Figure 2a), and precipitation shows the opposite characteristics of Northern Europe and Southern Europe as shown in Figure 1a. It can be seen from the time series (PC1) change curve that this type exhibits obvious interannual changes and also has a periodical characteristic. After the 1980s, it was almost all in a negative phase (Figure 2b). The contribution of the first-mode variance of the precipitation EOF analysis in Asia is 20.7\% (Figure 2c). The precipitation characteristics of Mongolia and Central Asia (excluding the Tibetan Plateau) are opposite. The time series (PC1) of this feature vector shows significant interannual changes (Figure 2d). The analysis results of EOF verified the existence of the effects of WPSST on CAMO and NESE. 

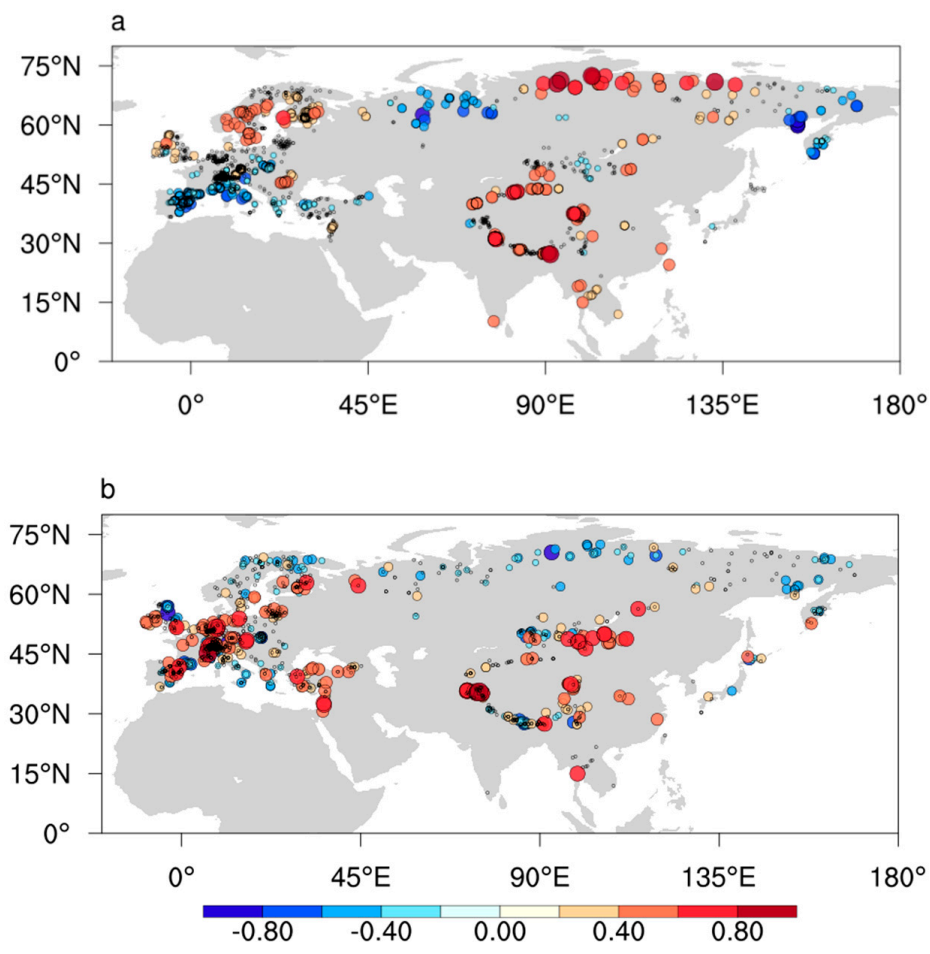

Figure 1. Correlation between annual precipitation in the Eurasian region and (a) annual Western Pacific Warm Pool sea surface temperature (WPSST), (b) tree-ring chronology during their common period from 1951 to 1990. The filled (open) circles in (a) and (b) indicate significant $(p<0.1)$ (insignificant) correlations.
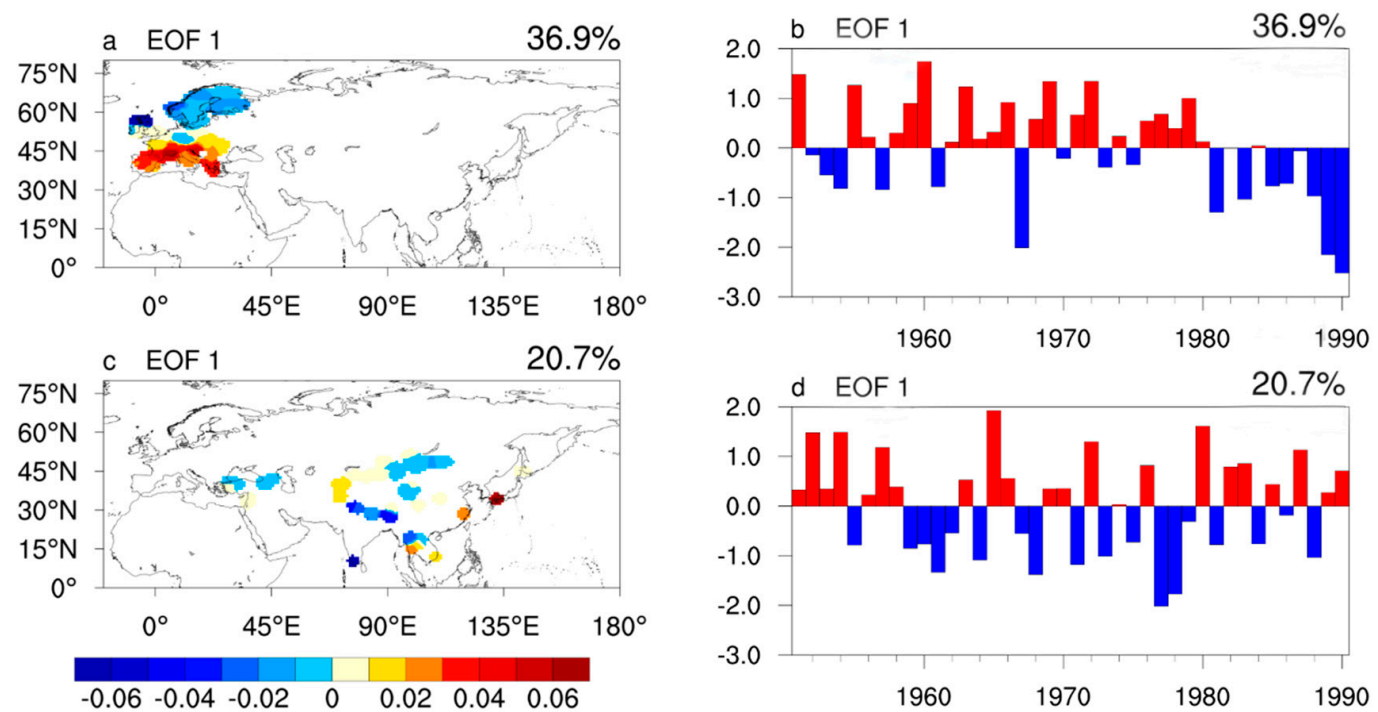

Figure 2. The first mode of empirical orthogonal function (EOF) of precipitation from 1951 to 1990 in (a) Europe and (c) Asia. The time series corresponding to the first mode of EOF in (b) Europe and (d) Asia. Only the precipitation sequences that show both a significant correlation between precipitation and WPSST (precipitation changes are affected by WPSST) and a significant positive correlation between tree-ring chronology and precipitation (the tree-ring chronology is sensitive to precipitation changes, and the tree-ring chronology can be used instead of studying precipitation changes).

When WPSST increased, precipitation in Central Asia and Nordic increased significantly, while precipitation in Mongolia and southern Europe decreased. The difference in annual precipitation between abnormally warm and cold WPSST years can reach $28 \%$ of the total annual precipitation (Figure 3a). The precipitation changes associated with extreme SST are similar to correlations between 
local precipitation and WPSST (Figure 1a). With the occurrence of an ENSO event, the annual precipitation difference in Europe, Mongolia, and Central Asia increased significantly (Figure 3b), which was consistent with the previously discovered influence of ENSO on precipitation events in Eurasia $[2,33]$. This indicates that the impacts of extreme WPSST on extreme precipitation changes in Eurasia are largely regulated by ENSO events.
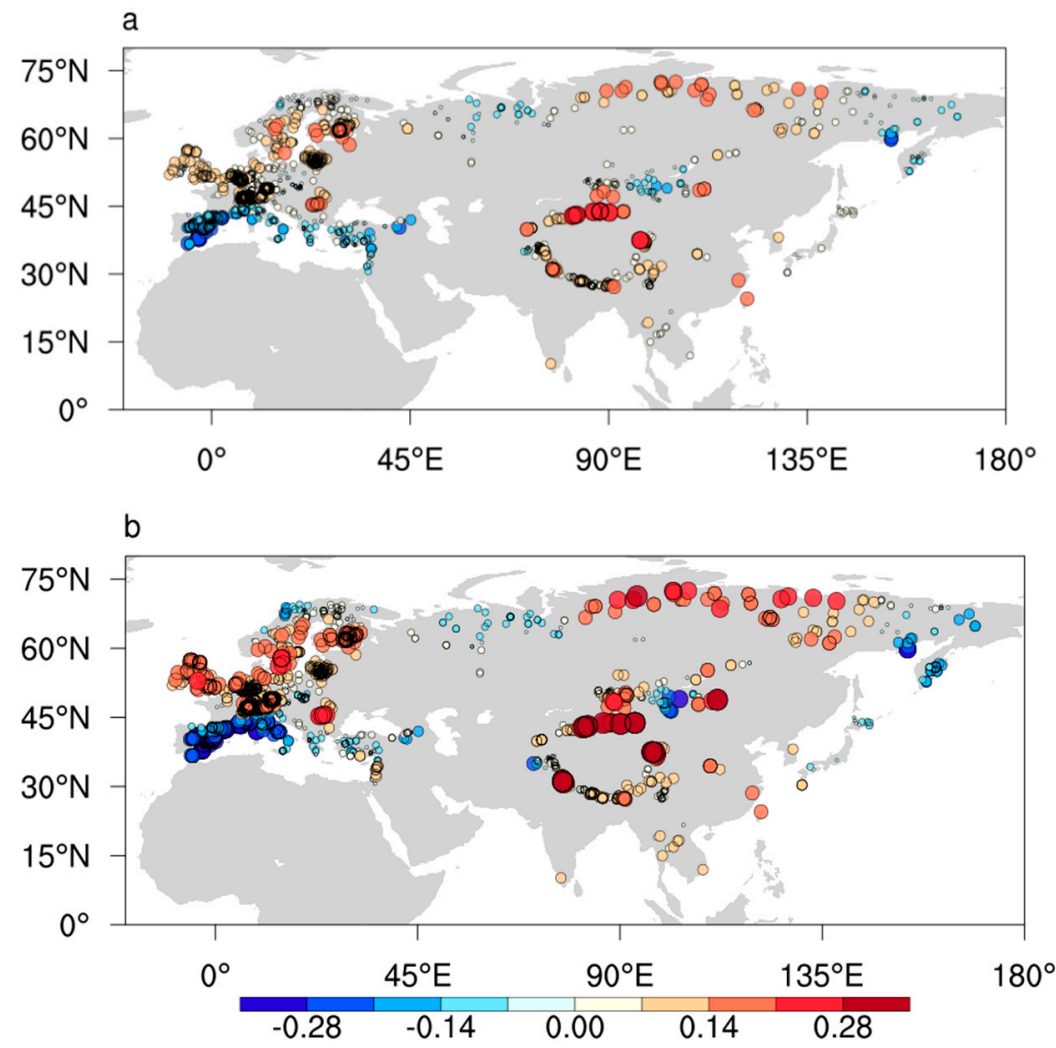

Figure 3. The differences between (a) WPSST abnormal warm and cold years; and (b) WPSST abnormal warm years (during La Niña) and abnormal cold years (during El Niño); annual precipitation is divided by annual average precipitation from 1951 to 1990.

3.2. Oceanic and Atmospheric Processes Linking Western Pacific Warm Pool Sea Surface Temperature and Precipitation in Eurasia

In this study, the large-scale atmospheric circulation associated with WPSST extreme warm and cold years in years with and without ENSO events is discussed. It was found that, under the background of ENSO events, the precipitation anomalies between WPSST extreme warm years and extreme cold years in Eurasia are more obvious, and the anomalies of sea level potential height field and wind field are also higher than those without ENSO events. This indicates that a WPSST anomaly coinciding with an ENSO event has a great influence on precipitation in Eurasia [33].

WPSST is significantly correlated with the $850 \mathrm{hPa}$ zonal wind field in Central Asia (Figure 4). The precipitation anomaly in Central Asia is mainly caused by zonal wind anomaly. Except for the Qinghai-Tibet Plateau, WPSST is negatively correlated with Central Asia zonal wind and positively correlated with Mongolian zonal wind, with a significance of $p<0.1$ (Figure 4b). When WPSST rises, the east wind anomaly is the main anomaly in Central Asia. The western Pacific warm and humid airflow brings abundant water vapor. The western Pacific subtropical high is located in the north, and there is more precipitation in Central Asia [24]. At this time, the Mongolian region was an inland dry and cold westerly anomaly; there was an anticyclonic circulation anomaly and an increase in atmospheric pressure (Figure 5a,b). As a result, precipitation in Mongolia is reduced and drought is prone to occurring. 

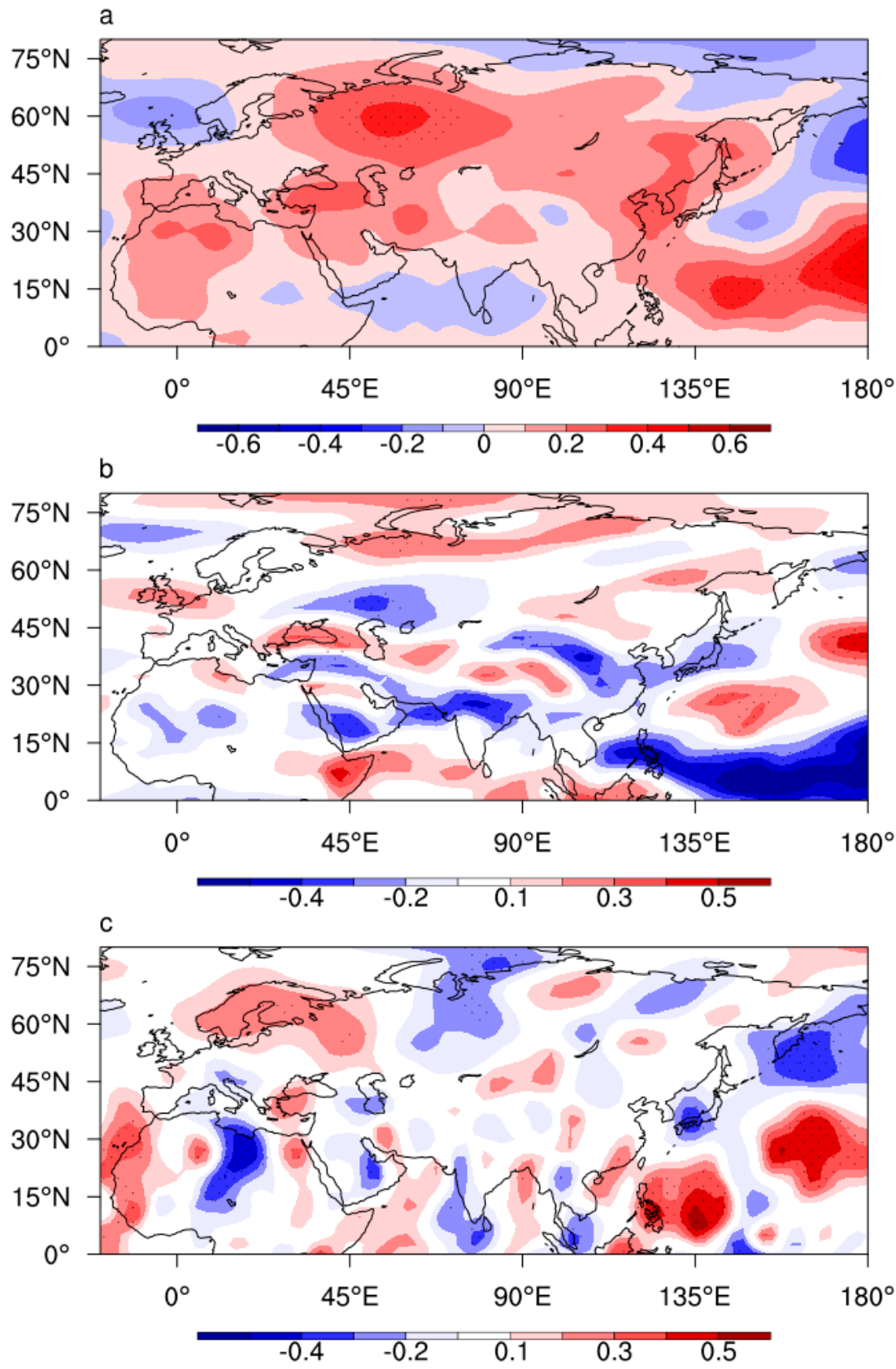

Figure 4. Correlation between (a) annual average $850 \mathrm{hPa}$ potential height field, (b) annual average $850 \mathrm{hPa}$ zonal wind, and (c) annual average $850 \mathrm{hPa}$ meridional wind during their common period from 1951 to 1990. Significant $(p<0.1)$ correlations in $(\mathbf{a}-\mathbf{c})$ are dotted shadow area.

In Europe, the effect of WPSST is more evident in $850 \mathrm{hPa}$ meridional wind. The variation of precipitation in Europe is mainly caused by the difference between $850 \mathrm{hPa}$ potential height field and meridional wind field circulation (Figure $4 \mathrm{a}, \mathrm{c}$ ). When WPSST rises, the pressure increase in southern Europe is much greater than in Northern Europe (Figure 5a), resulting in strong westerly anomalies over Europe and an enhanced North Atlantic jet stream [2]. At this time, the largest humidity advection axis over Europe is from southwest to northeast, from the Atlantic to the Nordics and Scandinavia [4]. Humidity transport is enhanced (weaker) in Northern (Southern) Europe, and there are (reverse) cyclonic circulation anomalies in Northern (Southern) Europe (Figure 5b). This results in warmer WPSST years in Northern Europe, where storms and humidity are higher than normal, while Southern Europe is drier than normal [34]. 

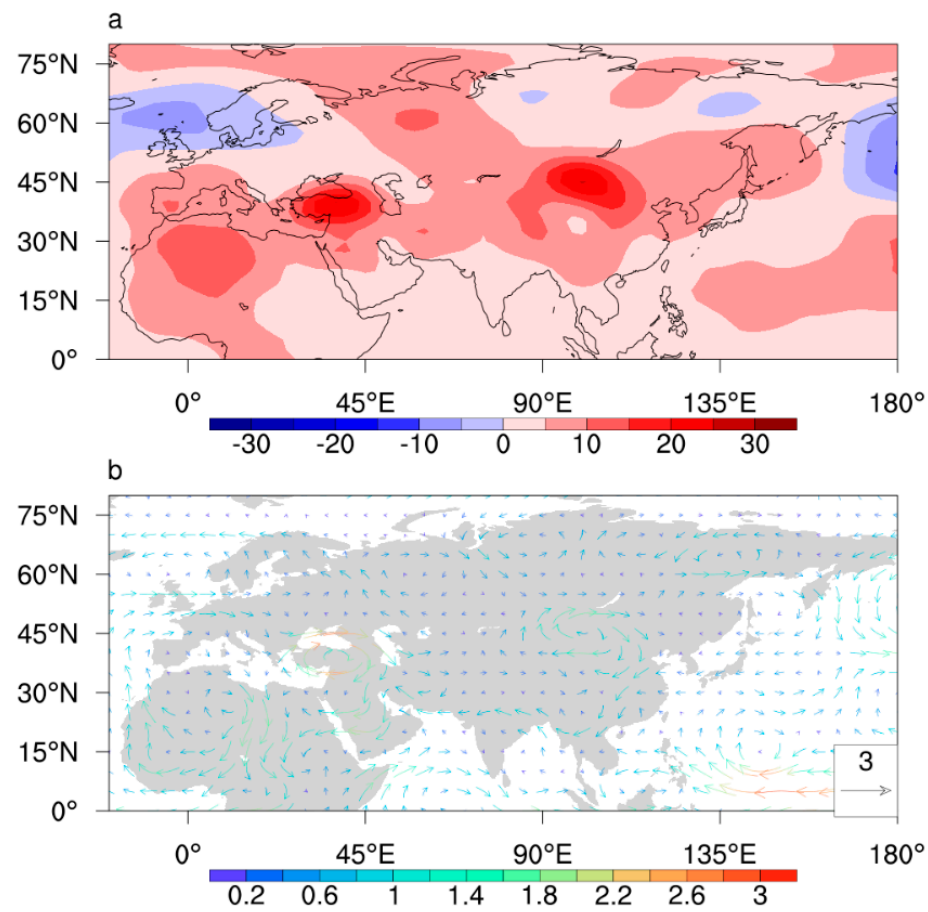

Figure 5. The difference between WPSST abnormal warm and cold years in (a) 850hPa potential height field, and (b) $850 \mathrm{hPa}$ wind field.

In a WPSST anomaly year with ENSO event, the difference between the potential height field and wind field is greater than that in WPSST anomaly years without ENSO events (Figure 6a,b). At the same time, in the warm WPSST year, the Nordics and Central Asia are more humid, and Southern Europe and Mongolia are less rainy (Figure 3b). Both the CAMO and NESE dipole types have increased intensities.
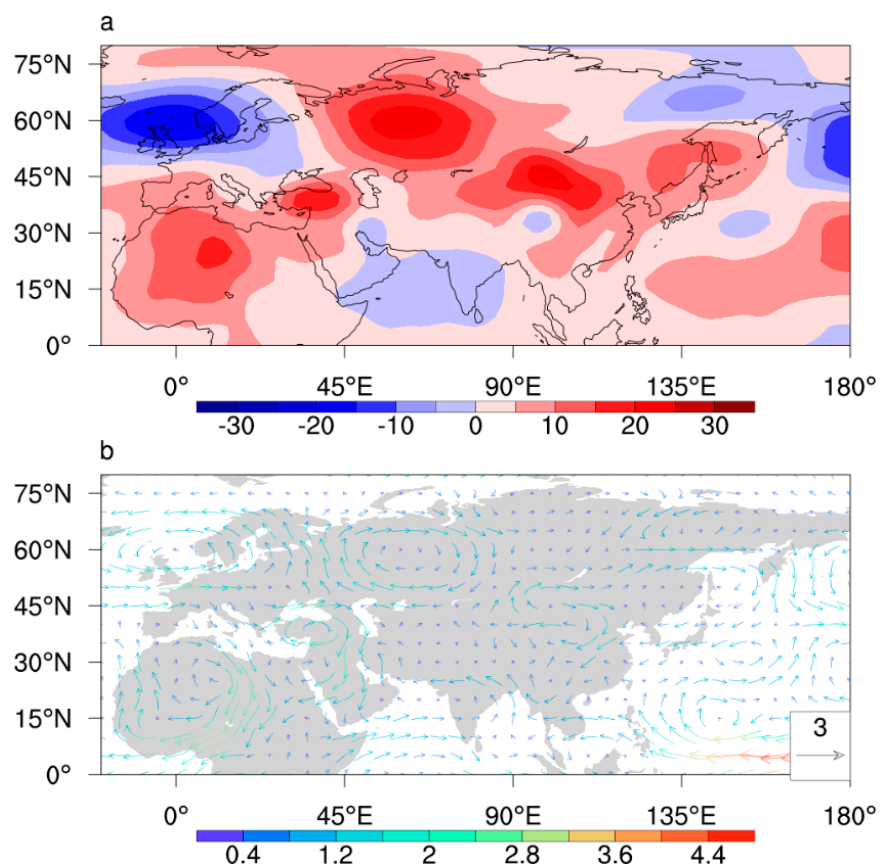

Figure 6. The difference between WPSST abnormal warm (during La Niña) and cold (during El Niño) years in an El Niño-Southern Oscillation (ENSO) context: (a) 850hPa potential height field; and (b) $850 \mathrm{hPa}$ wind field. 


\section{Relationship with Western Pacific Warm Pool Sea Surface Temperature since the Little Ice Age}

\subsection{Central Asia-Mongolia Dipole Mode}

Many annual rings in Eurasia are sensitive to precipitation. This study selected tree-ring chronologies that had a significant $(p<0.1)$ positive correlation with precipitation and a significant correlation with WPSST (Figures $1 \mathrm{~b}$ and 7). These tree-ring chronologies can represent local precipitation changes and reflect precipitation changes caused by WPSST. A total of 44 tree-ring chronologies met these conditions. Among them, there were 21 tree-ring chronologies in Asia and 23 in Europe. The response of precipitation-sensitive tree rings to the WPSST is very similar to the responses for precipitation in Eurasia, except for a few regions of Europe (Figures 1a and 7). This indicates that the annual rings sensitive to precipitation can better reflect the impact of WPSST on precipitation patterns.

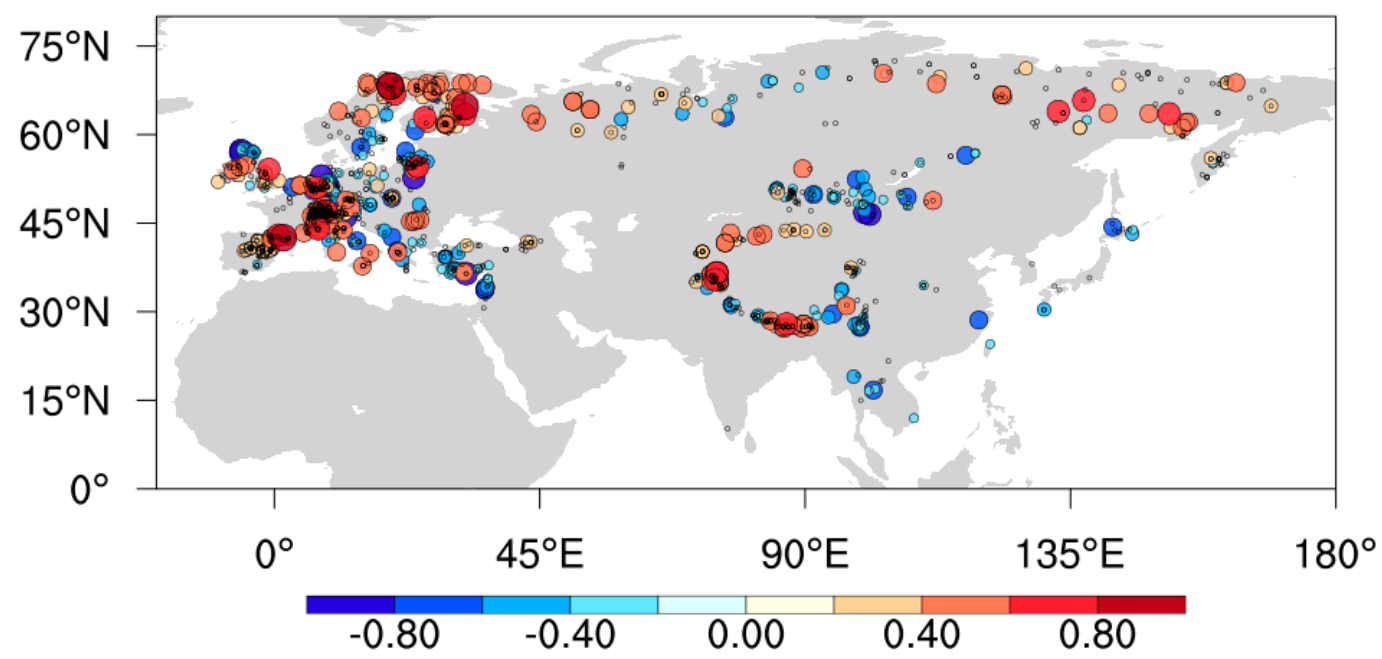

Figure 7. Correlation between the tree-ring chronology and annual WPSST during their common period from 1951 to 1990. The filled (open) circles indicates significant $(p<0.1)$ (insignificant) correlations.

For the CAMO dipole, there were six chronologies for Mongolia (negative correlation with WPSST) and seven chronologies for Central Asia (positively related to WPSST) (Figure 7). The chronology of the two regions is average, and the chronological length of each region is 1280-1990. The mean time series of two regions are reversely correlated with the WPSST. When WPSST rises, the precipitation in Mongolia (Central Asia) is reduced (increased) and the growth of trees is slowed down (accelerated). The growth of trees in Central Asia and Mongolia shows the reverse; that is, the chronology is negatively correlated. The stronger the negative phase of the correlation, the more significant the CAMO dipole. When the CAMO dipole is strong in historical periods, we may think that the increase in WPSST at this time caused the reduction of precipitation in Mongolia and the increase in precipitation in Central Asia. We calculated the running correlation based on a 41-year window of the standard chronology and the interdecadal chronology. As shown in Figure 8, this dipole is only significant on the interdecadal scale.

The CAMO dipole is only significant on the interdecadal timescale but not on interannual timescales (Figure 8), which may be because the ENSO signal is too strong on interannual timescales to mask the influence of the WPSST on interannual timescales [35]. The dipole variations on interdecadal timescales are less significant in modern periods than historical periods of the early 14 th, early 15 th, mid-17th and 18th centuries (Figure 8).

Because the chronology contained in the NESE dipole is too short, the total length of the chronology is less than two hundred years, so this paper does not analyze the historical changes of this dipole. 


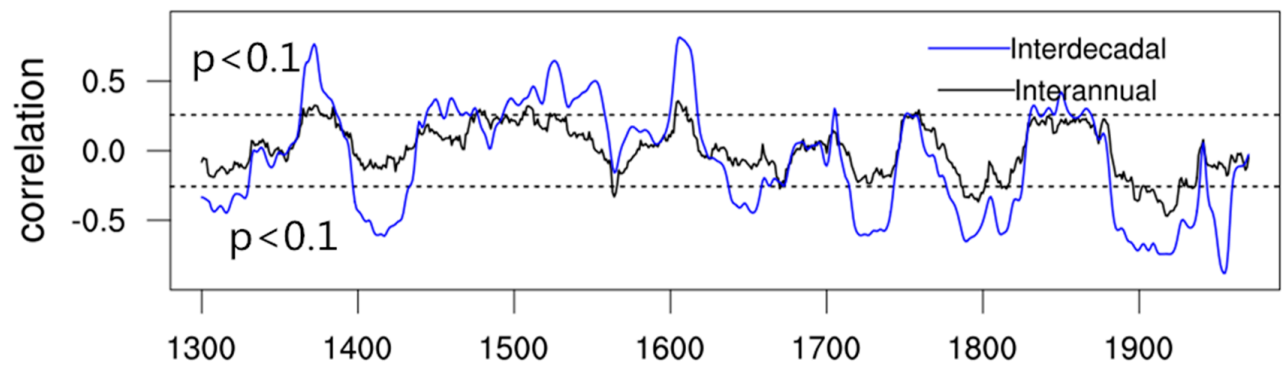

Figure 8. The running correlations between the interannual ( $0-9$ years, black) and interdecadal (10-100 years, blue) changes in the mean tree-ring series from Mongolia and Central Asia, using a 41-year window.

\subsection{Impact Factors}

Solar radiation is a key external force on climate change. As shown in Figure 9a, the interdecadal variations in solar radiation intensity are closely related to the intensity of the CAMO dipole. CAMO is particularly strong when the solar radiation is intensified. For example, since the LIA, CAMO has been intensified corresponding to the enhancement of the solar radiation. On the other hand, the CAMO pattern is very weak during the Maunder Minimum period (1645-1715) with weak solar radiation (Figure 9a). However, the positive correlation between the strength of the CAMO and solar irradiation has weakened in the 20th century, which may be caused by the intensification of human influence.

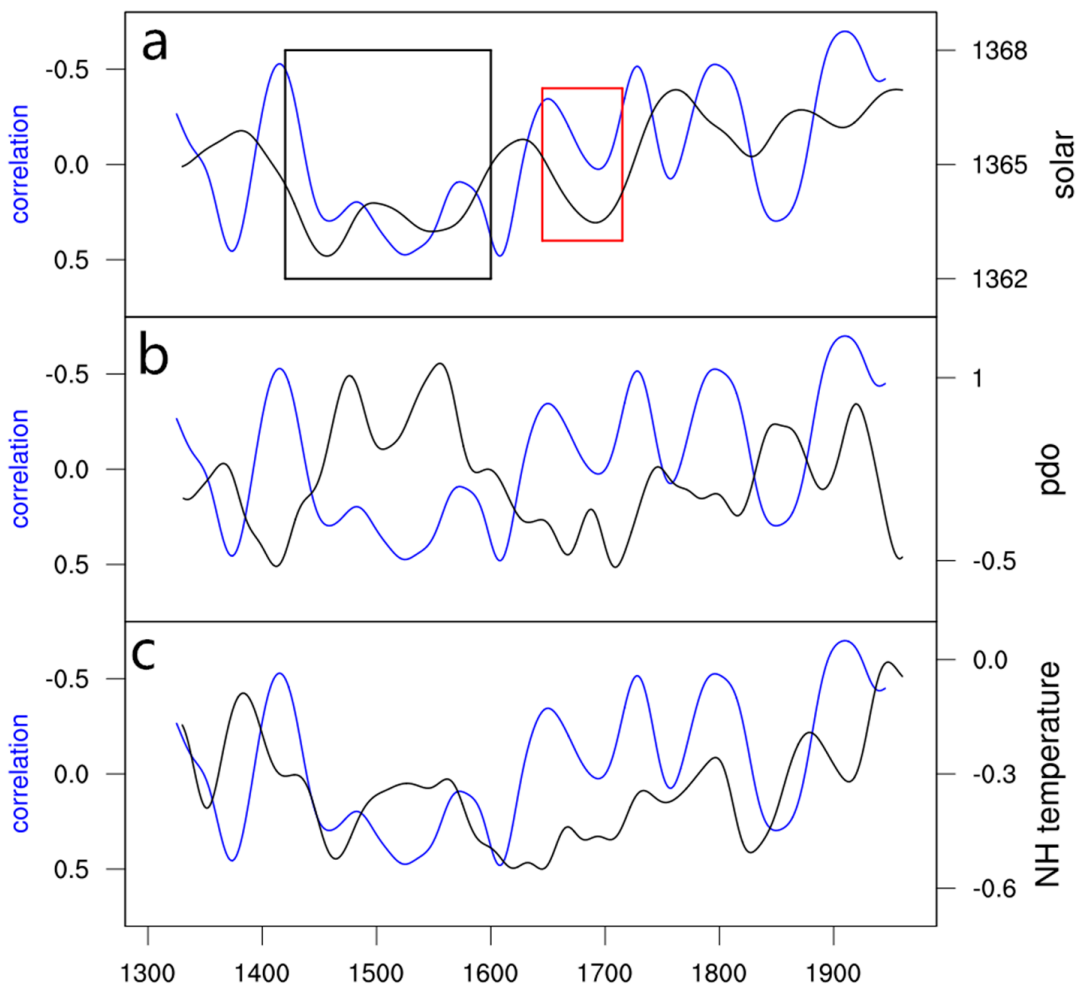

Figure 9. Comparison between the strength of the Central Asia-Mongolia (CAMO) dipole as indicated by the 41-year-window-based running correlation shown in Figure 5 (blue). (a) The solar radiation (black); (b) the reconstructed Pacific decadal oscillation (PDO) index (standardized index) (black); and (c) the Northern Hemisphere temperature (standardized index) (black) value. The Northern Hemisphere temperatures were produced as an average of the temperature reconstructions from Mann. These data were smoothed using a low-pass filter $(f<0.02)$ to facilitate visual comparison. 
In addition to being closely related to solar radiation, CAMO also showed close linkages with the temperature variations in the Northern Hemisphere (Figure 9c). When the solar radiation increases, the temperature in the Northern Hemisphere increases. At this time, ENSO is usually in the negative phase, that is, the La Nina state [29], corresponding to the rise of WPSST. There is an east wind anomaly in Central Asia, with warm and humid airflow from the ocean increasing; meanwhile, the inter-tropical convergence zone (ITCZ) and the western Pacific subtropical high are expanding and northward. This means that the east wind anomaly in Central Asia will also be northerly, which will enhance the northward transport of tropical air masses $[24,36,37]$. The anomalous changes in the wind field have brought abundant water vapor to Central Asia, which makes Central Asia rainier and wetter than at other times. At this time, the Mongolian region is a west wind anomaly (Figure 4b); a clockwise wind field anomaly and an increase in pressure field are not conducive to precipitation. The difference in precipitation between Central Asia and Mongolia is increased, and the CAMO dipole is enhanced.

In addition, the strength of CAMO is also closely related to PDO. The overall trend of the CAMO dipole has been consistent with PDO since LIA, and CAMO dipole is stronger when PDO is in the negative phase (Figure $9 \mathrm{~b}$ ). The reason for this phenomenon may be that the periodicity of PDO is obvious in multi-decade scale [38]. The PDO is a key modulator for the interdecadal variations of the WPSST. The WPSST is low (high) during the positive (negative) phase of PDO [39]. When WPSST is increased, precipitation in Mongolia is reduced, precipitation in central Asia is increased, and the negative correlation of tree-ring chronology in Mongolia and central Asia is enhanced, that is, the CAMO dipole is enhanced. PDO changes the WPSST, which in turn causes changes in precipitation in the Eurasian region that are regulated by WPSST. This can explain the inverse correlation between the CAMO dipole and the PDO. However, when the PDO index had a strong positive value, the CAMO dipole intensity at this time was not as weak as before in the first half of the 20th century, which may be due to the dramatic increase in the temperature of the contemporary warm period.

\section{Conclusions}

This paper analyzes the impact of WPSST on precipitation in Eurasia since LIA. The main conclusions are as follows:

(1) In Asia, there is a CAMO dipole in which precipitation is regulated by WPSST. The precipitation increases (decreases) in Central Asia (Mongolia) when WPSST rises. In Europe, a NESE dipole with a positive (negative) correlation between WPSST was found, and precipitation increases (decreases) in Northern (Southern) Europe when WPSST rises.

(2) The impact of WPSST anomalies on precipitation changes in Eurasia is largely regulated by ENSO. When there is an ENSO positive (negative) phase event, the corresponding WPSST decreases (increases), and the decreases (increases) of precipitation in Central Asia and Northern Europe and the increases (decreases) in precipitation in Mongolia and Southern Europe are more obvious. Both CAMO and NESE dipole strengths increase.

(3) The impact of WPSST on precipitation in Europe and Asia is mainly generated by atmospheric circulation. When WPSST is increased, Central Asia is mainly an east wind anomaly. The warm and humid airflow bring abundant water vapor, and the precipitation in East Asia increases. Mongolia has dry-cold west wind with reduced precipitation. The difference in precipitation between Central Asia and Mongolia is strengthened and the CAMO dipole is enhanced. At the same time, when WPSST rises, the wind field over the European continent is from southwest to northeast. The humidity transmission in Northern (Southern) Europe is enhanced (weakened). Northern (Southern) Europe has an obvious (reverse) cyclonic circulation. The moisture in Northern Europe is above average, while Southern Europe is drier, and the NESE dipole is enhanced.

(4) The CAMO dipole of 1280-1990 was reconstructed using the tree-ring chronology. This dipole has a significant correlation on the interdecadal scale. The CAMO dipole has a positive correlation with solar radiation and the temperature in the Northern Hemisphere since the LIA. When the 
solar radiation is enhanced and the temperature in the Northern Hemisphere is increased, the WPSST is increased and the dipole is enhanced. The CAMO dipole is negatively correlated with PDO, and the periodicity of CAMO on the interdecadal scale is consistent with the PDO period. The intensity of the CAMO dipole is enhanced when the PDO is weakened. During the contemporary warm period since the industrial age, the CAMO dipole was still extremely strong during periods when the increase in solar radiation is not obvious and the PDO is not significantly weakened, which may be mainly due to the sharp increases in temperature caused by industrial activities.

Author Contributions: Conceptualization, K.F.; Data curation, Z.D.; Formal analysis, F.Z.; Methodology, J.D. and P.Z.; Data curation \& Writing original draft, H.L.; Writing review \& editing, G.H. All authors have read and agreed to the published version of the manuscript.

Funding: This research was funded by the National Science Foundation of China (Grant Numbers: 41971022, 41822101 and 41772180), the Strategic Priority Research Program of the Chinese Academy of Sciences (Grant Number: XDB26020000), fellowship for the National Youth Talent Support Program of China (Ten Thousand People Plan), fellowship for Youth Talent Support Program of Fujian Province and the innovation team project (Grant Number: IRTL1705). This research was also funded by the Swedish Formas (Future Research Leaders Project) and VR projects, the Strategic Priority Research Program of Chinese Academy of Sciences (Grant Number: XDA20060501), the National Key R\&D Program of China (Grant Number: 2018YFA0605904). This research was also supported by the National Natural Science Foundation of China (Grant Numbers: 41831175, 91937302 and 41721004).

Acknowledgments: We acknowledge the dendrochronologists and climatologists who made their tree-ring and climate data public available.

Conflicts of Interest: The authors declare no conflict of interest.

\section{References}

1. Barros, V.; Stocker, T.F. Managing the risks of extreme events and disasters to advance climate change adaptation: Special report of the Intergovernmental Panel on Climate Change. J. Clin. Endocrinol. Metab. 2012, 18, 586-599.

2. Zhang, W.; Wang, L.; Xiang, B.; Qi, L.; He, J. Impacts of two types of La Niña on the NAO during boreal winter. Clim. Dyn. 2015, 44, 1351-1366. [CrossRef]

3. Dinezio, P.N.; Tierney, J.E. The effect of sea level on glacial Indo-Pacific climate. Nat. Geosci. 2013, 6, 485-491. [CrossRef]

4. Zanardo, S.; Nicotina, L.; Hilberts, A.G.J.; Jewson, S.P. Modulation of economic losses from European floods by the North Atlantic Oscillation. Geophys. Res. Lett. 2019, 46, 2563-2572. [CrossRef]

5. Nitta, T. Convective activities in the tropical western Pacific and their impact on the Northern Hemisphere summer circulation. J. Meteorol. Soc. Jpn. Ser. II 1987, 65, 373-390. [CrossRef]

6. Chen, G.; Fang, C.; Zhang, C.; Chen, Y. Observing the coupling effect between warm pool and "rain pool" in the Pacific Ocean. Remote Sens. Environ. 2004, 91, 153-159. [CrossRef]

7. DiNezio, P.N.; Clement, A.; Vecchi, G.A.; Soden, B.; Broccoli, A.J.; Otto-Bliesner, B.L.; Braconnot, P. The response of the Walker circulation to Last Glacial Maximum forcing: Implications for detection in proxies. Paleoceanogr. Paleoclimatology 2011, 26. [CrossRef]

8. Mohtadi, M.; Prange, M.; Oppo, D.W.; Pol-Holz, R.D.; Ute, M.; Zhang, X.; Steinke, S.; Luckge, A. North Atlantic forcing of tropical Indian Ocean climate. Nature 2014, 509, 76-80. [CrossRef]

9. Hoerling, M.P. Tropical Origins for Recent North Atlantic Climate Change. Science 2001, 292, 90-92. [CrossRef]

10. Huang, R.; Sun, F. Interannual variation of the summer teleconnection pattern over the northern hemisphere and its numerical simulation. Chin. J. Atmos. Sci. 1992, 16, 52-61. (In Chinese)

11. Min, J.Z.; Li, C.; Wu, P. A Study of the relationship between summer tropical convection over the western pacific and the rainfall in the middle-lower reaches of the Yangtze River. Chin. J. Atmos. Sci. 2005, 29, 947-954. (In Chinese)

12. Kucharski, F.; Molteni, F.; Bracco, A. Decadal interactions between the western tropical Pacific and the North Atlantic Oscillation. Clim. Dyn. 2006, 26, 79-91. [CrossRef] 
13. Hurrell, J.W.; Hoerling, M.P.; Phillips, A.S.; Xu, T. Twentieth century North Atlantic climate change. Part I: Assessing determinism. Clim. Dyn. 2004, 23, 371-389. [CrossRef]

14. Hoerling, M.P.; Hurrell, J.W.; Xu, T.; Bates, G.T.; Phillips, A.S. Twentieth century North Atlantic climate change. Part II: Understanding the effect of Indian Ocean warming. Clim. Dyn. 2004, 23, 391-405. [CrossRef]

15. Allen, S.K.; Plattner, G.K.; Nauels, A.; Xia, Y.; Stocker, T.F. Climate Change 2013: The Physical Science Basis. An overview of the Working Group 1 contribution to the Fifth Assessment Report of the Intergovernmental Panel on Climate Change (IPCC); EGU General Assembly: Lund, Sweden, 2014; Volume 16.

16. Hughes; Malcolm, K. Dendroclimatology: Progress and Prospects; Thomas, W.S., Diaz, H.F., Eds.; Science \& Business Media: Berlin/Heidelberg, Germany, 2010; Volume 11.

17. Yang, B.; Qin, C.; Wang, J.; He, M.; Melvin, T.M.; Osborn, T.J.; Briffa, K.R. A 3,500-year tree-ring record of annual precipitation on the northeastern Tibetan Plateau. Proc. Natl. Acad. Sci. USA 2014, 111, 2903-2908. [CrossRef] [PubMed]

18. Gou, X.; Deng, Y.; Gao, L.; Chen, F.; Cook, E.; Yang, M.; Zhang, F. Millennium tree-ring reconstruction of drought variability in the eastern Qilian Mountains, northwest China. Clim. Dyn. 2015, 45, 1761-1770. [CrossRef]

19. Kaiser, K.F.; Friedrich, M.; Miramont, C.; Kromer, B.; Sgier, M.; Schaub, M.; Boeren, I.; Remmele, S.; Talamo, S.; Guibal, F.; et al. Challenging process to make the Lateglacial tree-ring chronologies from Europe absolute-An inventory. Quat. Sci. Rev. 2012, 36, 78-90. [CrossRef]

20. Cook, E.R. A Time Series Analysis Approach to Tree Ring Standardization. Ph.D. Thesis, The University of Arizona, Tucson, AZ, USA, 1985.

21. Kirdyanov, A.V.; Treydte, K.S.; Nikolaev, A.; Helle, G.; Schleser, G.H. Climate signals in tree-ring width, density and $\delta 13 C$ from larches in Eastern Siberia (Russia). Chem. Geol. 2008, 252, 31-41. [CrossRef]

22. Cook, E.R.; Krusic, P.J.; Anchukaitis, K.J.; Buckley, B.M.; Nakatsuka, T.; Sano, M. PAGES Asia2k Members. Tree-ring reconstructed summer temperature anomalies for temperate East Asia since 800 C.E. Clim. Dyn. 2013, 41, 2957-2972. [CrossRef]

23. Hirahara, S.; Ishii, M.; Fukuda, Y. Centennial-scale sea surface temperature analysis and its uncertainty. J. Clim. 2014, 27, 57-75. [CrossRef]

24. Huang, R.; Sun, F. Impacts of the Thermal State and the Convective Activities in the Tropical Western Warm Pool on the Summer Climate Anomalies in East Asia. Chin. J. Atmos. Sci. 1994, 18, 141-151. (In Chinese)

25. Jin, Z.; Chen, W. Study on the influence of sea surface water warming anomaly on the East Asian summer monsoon in the western Pacific warm pool area. Atmos. Sci. 2002, 26, 57-68. (In Chinese)

26. Kalnay, E.; Kanamitsu, M.; Kistler, R.; Collins, W.; Deaven, D.; Gandin, L.; Iredell, M.; Saha, S.; White, G.; Woollen, J.; et al. The NCEP-NCAR 40-year reanalysis project. Bull. Am. Meteor. Soc. 1996, 77, 437-472. [CrossRef]

27. MacDonald, G.M.; Case, R.A. Variations in the Pacific Decadal Oscillation over the past millennium. Geophys. Res. Lett. 2005, 32. [CrossRef]

28. Bard, E.; Raisbeck, G.; Yiou, F.; Jouzel, J. Solar irradiance during the last 1200 years based on cosmogenic nuclides. Tellus B 2000, 52, 985-992. [CrossRef]

29. Mann, M.E.; Zhang, Z.; Rutherford, S.; Bradley, R.S.; Hughes, M.K.; Shindell, D.; Ammann, C.; Faluvegi, G. Global signatures and dynamical origins of the Little Ice Age and Medieval Climate Anomaly. Science 2009, 326, 1256-1260. [CrossRef] [PubMed]

30. Qian, W.; Hu, Q.; Zhu, Y.; Lee, D.K. Centennial-scale dry-wet variations in East Asia. Clim. Dyn. 2003, 21, 77-89. [CrossRef]

31. Peng, Z.; Wang, Q.J.; Bennett, J.C.; Pokhrel, P.; Wang, Z. Seasonal precipitation forecasts over China using monthly large-scale oceanic-atmospheric indices. J. Hydrol. 2014, 519, 792-802. [CrossRef]

32. Sutton, R.T.; Hodson, D.L.R. Atlantic Ocean forcing of North American and European summer climate. Science 2005, 309, 115-118. [CrossRef]

33. Lupo, A.R.; Mokhov, I.I.; Chendev, Y.G.; Lebedeva, M.G.; Akperov, M.; Hubbart, J.A. Studying summer season drought in western Russia. Adv. Meteorol. 2014, 2014. [CrossRef]

34. Folland, C.K.; Knight, J.; Linderholm, H.W.; Fereday, D.; Ineson, S.; Hurrell, J.W. The summer North Atlantic Oscillation: Past, present, and future. J. Clim. 2009, 22, 1082-1103. [CrossRef]

35. Liu, Y.; Cobb, K.M.; Song, H.; Li, Q.; Li, C.Y.; Nakatsuka, T.; Linderholm, H.W. Recent enhancement of central Pacific El Nino variability relative to last eight centuries. Nat. Commun. 2017, 8, 15386. [CrossRef] [PubMed] 
36. Yan, H.; Wei, W.; Soon, W.; An, Z.; Zhou, W.; Liu, Z.; Wang, Y.; Carter, R.M. Dynamics of the intertropical convergence zone over the western Pacific during the Little Ice Age. Nat. Geosci. 2015, 8, 315-320. [CrossRef]

37. Liu, J.; Wang, B.; Cane, M.A.; Yim, S.; Lee, J. Divergent global precipitation changes induced by natural versus anthropogenic forcing. Nature 2013, 493, 656-659. [CrossRef] [PubMed]

38. Allan, R.; Lindesay, J.; Parker, D. El Niño Southern Oscillation and Climatic Variability. N. Z. Geogr. 1998, 54, 64-65.

39. Fang, K.; Cook, E.; Guo, Z.; Chen, D.; Ou, T.; Zhao, Y. Synchronous multi-decadal climate variability of the whole Pacific areas revealed in tree rings since 1567. Environ. Res. Lett. 2018, 13, 024016. [CrossRef]

(C) 2020 by the authors. Licensee MDPI, Basel, Switzerland. This article is an open access article distributed under the terms and conditions of the Creative Commons Attribution (CC BY) license (http://creativecommons.org/licenses/by/4.0/). 